\title{
O PERFIL DA PRODUÇÃO CIENTÍFICA ONLINE EM PORTUGUÊS RELACIONADA ÀS MODALIDADES OLIIMPICAS E PARALÍMPICAS
}

\author{
EL PERFIL DE LA PRODUCCIÓN CIENTÍFICA ONLINE EN PORTUGUÉS \\ RELACIONADA CON LAS MODALIDADES DEPORTIVAS OLÍMPICAS Y \\ PARALÍMPICAS
}
THE PROFILE OF ONLINE SCIENTIFIC PRODUCTION IN PORTUGUESE ON OLYMPIC AND PARALYMPIC SPORTS

Doralice Lange Souza*, Marcelo Moraes e Silva*, Tatiana Sviesk Moreira*

\author{
Palavras-chave \\ Atividades científicas \\ e tecnológicas. \\ Pesquisa. \\ Publicações \\ periódicas. Esportes.
}

Resumo: 0 objetivo deste trabalho foi explorar o perfil da produção científica online em português relacionada às modalidades esportivas olímpicas e paralímpicas. Foram consultados o Lilacs, Medline, Scielo e Portal de Periódicos da Capes. Tomaram-se como descritores os nomes oficiais das modalidades e termos correlatos. Localizaram-se 2.007 artigos, 2.000 sobre modalidades de verão e sete de inverno. Dentre os que discutem modalidades de verão, 1.956 se referem às olímpicas e 52 às paralímpicas. A modalidade olímpica de verão com mais produção é o futebol (608 trabalhos) e a paralímpica é a natação (13). A maioria dos artigos versa sobre treinamento (773). Dos 3.531 autores listados nos artigos, 1.965 têm formação em Educação Física/Esporte. Os principais centros de produção estão em São Paulo. Este estudo oferece subsídios para o fomento de pesquisas em áreas mais necessitadas e estratégicas do esporte.

Resumen: El objetivo de este trabajo fue explorar el perfil de la producción científica online en portugués relacionada con las modalidades olímpicas y paralímpicas. Se consultaron Lilacs, Medline, Scielo y el Portal de Periódicos de la CAPES. Se tomaron como descriptores los nombres oficiales de las modalidades y los términos correlacionados. Se localizaron 2007 artículos, 2000 relativos a las modalidades de verano y siete sobre las de invierno. Entre los que discuten modalidades de verano, 1956 se refieren a las olímpicas y 52 a las paralímpicas. La modalidad olímpica de verano con más producción es el fútbol (608 trabajos) y la paralímpica es la natación (13). La mayoría de los artículos tratan sobre el entrenamiento (773). De los 3531 autores, 1965 tienen formación en Educación Física/Deporte. Los principales centros de producción están en São Paulo. Este estudio ofrece soporte para el fomento de investigaciones científica en áreas más necesitadas y estratégicas del deporte.

Abstract: This study aimed at exploring the profile of online scientific literature in Portuguese related to Olympic and Paralympic sports. The research was based on the following databases: Lilacs, Medline, Scielo, and the CAPES Portal. The descriptors included Olympic and Paralympic sports' official names and related terms. The search located 2,007 articles $-2,000$ related to summer sports and seven to winter sports. Among the former, 1,956 articles were related to Olympic and 52 to Paralympic sports. The Olympic sport with most articles is football (608 articles) and the main Paralympic sport is swimming (13). Most papers address training (773). Among the 3,531 authors listed in the papers, 1965 are trained in Physical Education/Sports. The main production centers are in São Paulo. This study provides support for the development of research in the most strategic and needed areas of sport.
* Universidade Federal do Paraná Curitiba, PR, Brasil.

E-mail: marcelomoraes@ufpr.br

Recebido em: 06-05-2016 Aprovado em: 14-07-2016 (c) (1) (8) Licence 


\section{INTRODUÇÃO}

O desporto moderno surgiu como uma emanação e expressão fidedignas dos princípios da sociedade industrial. Entre eles contam-se, como referências cimeiras e estruturantes, o princípio e a procura pelo rendimento. À medida que a sociedade evoluiu da indústria para os serviços outros valores entraram a determinar a sua configuração dita pós-moderna ou pós-industrial. Também o desporto se transformou, cindindo-se numa pluralidade de motivos e finalidades, de sujeitos e praticantes, de modelos e cenários. Se antes era uma atividade quase que exclusivamente orientada e estruturada para o alto rendimento e a competição organizada, para afirmação de estereótipos da juventude forte e saudável, da virilidade e masculinidade, o desporto passou paulatinamente a ser uma prática aberta a todas as pessoas e idades e a todos os estados de condição física e sociocultural. Expandiu-se e conquistou novas terras; ou seja, à vocação original de excelência e de alto rendimento adicionou a instrumentalização ao serviço das mais distintas finalidades: saúde, recreação e lazer, aptidão e estética corporal, reabilitação e inclusão etc. (BENTO, 2014, p.141).

As reflexões levantadas pelo intelectual português Jorge Bento (2014) demonstram que anteriormente o fenômeno esportivo era visto quase que exclusivamente como uma atividade voltada e estruturada em torno do rendimento. Contudo, o autor também salienta que hodiernamente tal manifestação cultural vem ganhando novos sentidos e significados, passando a ser vista de forma polissêmica, apresentando uma diversidade de sentidos e formas, tornando-se um fenômeno mais amplo e plural.

Essa condição polissêmica do esporte é uma demanda que também tende a repercutir no campo científico, ou seja, os diferentes contornos apresentados pelas manifestações esportivas apresentam peculiaridades a serem levantadas, investigadas e analisadas pelo universo científico a fim de que se compreenda o fenômeno na sua complexidade. Neste sentido, o objetivo geral deste trabalho foi explorar o perfil da produção científica online em língua portuguesa relacionada às modalidades esportivas olímpicas e paralímpicas. Para atingir este objetivo, tomaram-se como base as seguintes questões norteadoras: Como se comparam os níveis de produção científica entre o esporte olímpico e paralímpico? Quais modalidades esportivas têm sido privilegiadas pela produção em língua portuguesa? Quais os principais enfoques temáticos dos artigos publicados? Quais os principais autores e centros de produção dos artigos? Qual é o grau de formação dos autores e quais suas áreas de formação?

\section{METODOLOGIA}

A pesquisa buscou fontes nas seguintes bases de dados: Lilacs e Medline através da interface da Biblioteca Virtual da Saúde (Bvs - Bireme - www.bvsalud.org); Portal Scielo (www. scielo.org/php/index.php); e Portal de Periódicos da Capes (www.periodicos.capes.gov.br/). Os descritores utilizados para as buscas foram: (1) Nome oficial das modalidades olímpicas e paralímpicas em português e inglês, conforme o site do Comitê Olímpico Internacional (COI) (www.olympic.org) e do Comitê Paralímpico Internacional (IPC) (www.paralympic.org); (2) Termos relativos às modalidades olímpicas e paralímpicas em português e inglês, presentes nos sites do Comitê Olímpico Brasileiro (www.timebrasil.cob.org.br/esportes) e Comitê Paralímpico Brasileiro (www.cpb.org.br/modalidades); (3) Para os descritores referentes às modalidades olímpicas e paralímpicas de inverno, foram consultados também os sites da Confederação Brasileira de Desportos na Neve (CBDN) (www.cbdn.org.br) e da Confederação Brasileira de Desportos no Gelo (CBDG) (http://cbdg.org.br); (4) Equivalentes dos nomes oficiais das 
modalidades, em português e em inglês, de acordo com a Biblioteca Virtual em Saúde. Estes termos foram encontrados na lista de Descritores em Ciências da Saúde sistematizada pela Bireme e disponível na Bvs (www.bvsalud.org); (5) Palavras comumente associadas às modalidades tais como o nome designado aos seus praticantes (ex. basquetebolista, pugilista, ciclista, esgrimista, ginasta etc.) e os nomes antigos e/ou conhecidos popularmente das diversas modalidades esportivas (ex. ginástica olímpica).

Os critérios de inclusão foram os seguintes: (1) Artigos completos em português que, perante a utilização dos mecanismos de busca das bases de dados, continham os descritores em seu título, resumo e/ou assunto e tratavam de tópicos pertinentes às modalidades olímpicas e paralímpicas; (2) Artigos completos em português que incluíam os descritores listados em seu resumo e/ou assunto e que, embora não discutissem uma ou mais modalidades olímpicas e paralímpicas em específico, tratavam de temas que podem se aplicar a elas e/ou aos seus praticantes; (3) Posicionamentos oficiais de organizações científicas e entrevistas com pesquisadores que aparecem como artigos em diversas revistas.

Foram excluídos artigos publicados em outras línguas, bem como resenhas e textos que, embora citassem o nome de uma ou mais modalidades olímpicas ou paralímpicas e/ou algum dos outros descritores listados nos resumos, não tinham como foco alguma temática diretamente relacionada às modalidades olímpicas e paralímpicas em suas diferentes manifestações. Os artigos encontrados em mais de uma base de dados foram considerados uma única vez.

Após a coleta, os dados foram inseridos em uma planilha eletrônica onde foram identificadas as seguintes informações: a) título da publicação; b) nome dos autores; c) área de formação dos autores em nível de graduação; d) titulação; e) instituição de vínculo; f) nome do periódico no qual 0 artigo foi publicado; g) modalidade, submodalidade e especialidade; h) modalidade olímpica e/ ou paralímpica; i) instituições envolvidas na publicação; j) órgãos de fomento da pesquisa; k) tipo de pesquisa; I) link, m) referência completa do artigo; e n) enfoque temático do artigo.

Os dados relativos à instituição de vínculo dos autores foram extraídos dos próprios artigos. Já no caso de outras informações, tais como sua área de formação em nível de graduação e sua titulação, foram coletadas nas Plataformas Lattes (www.lattes.cnpq.br) nos pesquisadores brasileiros e da Plataforma DeGóis (http://www.degois.pt/globalindex.jsp) no caso de autores portugueses. Essas plataformas foram utilizadas pois os autores produtores de artigos eram oriundos basicamente do Brasil e de Portugal.

Uma das principais informações compiladas refere-se aos enfoques dos artigos. Para organizar os dados levantados foram criadas categorias que agrupassem os temas identificados. As ordenações criadas não foram definidas a priori. Todas foram testadas baseadas em sistematizações já desenvolvidas como, por exemplo, as diferentes áreas do conhecimento elaboradas pelo Directory of Sport Sciences da International Council of Sport Science and Physical Education (TALBOTT; HAAG; KESKINEN, 2013). No entanto, constatouse que as sistematizações disponíveis não ajudavam a entender os enfoques temáticos dos textos compilados. Desta forma, as categorias foram criadas indutivamente e elencadas a partir dos temas que emergiram na leitura dos resumos e, em alguns casos, dos textos completos. As categorias desenvolvidas são as seguintes:

- Treinamento: espaços e equipamentos relacionados à performance; aperfeiçoamento motor e aspectos fisiológicos, técnicos, táticos e biomecânicos relacionados com o rendimento. 
- Iniciação Esportiva e Categorias de Base: metodologia de ensino, aprendizagem motora, treinamento de jovens atletas e seleção de talentos esportivos.

- Saúde: promoção, manutenção e reabilitação da saúde, lesões e patologias.

- Aspectos Educacionais: aspectos pedagógicos e educacionais do esporte na escola e em processos de escolarização.

- Administração, Financiamento e Políticas Públicas: legislação, gestão, administração e financiamento do esporte.

- Lazer: esporte relacionado com a recreação, lazer e turismo.

- Regras e Arbitragem: regulamento esportivo, perfil, formação, treinamento e atuação de árbitros.

- Técnicos e treinadores: formação, atuação e perfil de técnicos e treinadores.

- Aspectos sociais, culturais e históricos: aspectos sociológicos, antropológicos e históricos relacionados com o esporte (discussões sobre temáticas tais como gênero, mídia, marketing, violência, valores etc.).

- Aspectos Psicológicos: motivação, emoções, autoimagem, transtornos psicológicos/ alimentares, personalidade, concentração, comportamento e humor.

- Aspectos Nutricionais: perfil dietético e suplementação alimentar.

Os procedimentos para a coleta, arquivamento e análise dos dados se inspiram nas contribuições de Van Tulder et al. (2003). A definição e o refinamento dos descritores, critérios de inclusão e exclusão dos artigos, bem como métodos de busca nas bases de dados, foram realizados por todos os pesquisadores envolvidos na pesquisa. Tendo definido essas questões, foi utilizada a técnica de cross-checking entre os pesquisadores, ou seja, dois ou mais investigadores utilizaram as mesmas fontes de busca e critérios de inclusão e exclusão e classificaram os artigos de forma independente como "elegíveis", "inelegíveis" e "questionáveis". Compararam-se os resultados e, nos casos "questionáveis", e/ou quando houve incompatibilidade entre os resultados dos pesquisadores, os critérios de busca e de inclusão e exclusão foram discutidos contrastando-os com os objetivos de cada um dos artigos até que se alcançasse consenso quanto à sua inserção, ou não, na pesquisa. Adotaram-se procedimentos similares para a definição das categorias temáticas, tendo sempre dois ou mais investigadores classificando os artigos de forma independente até a definição da(s) categoria(s) de cada artigo.

\section{RESULTADOS E DISCUSSÃO}

\subsection{Perfil da produção}

Ao considerar os critérios de inclusão e exclusão preestabelecidos, até dezembro de 2015 as bases de dados consultadas somaram 2.007 artigos, dentre os quais, 2.000 sobre modalidades de verão $(\sim=99,65 \%)$ e sete sobre modalidades de inverno $(\sim=0,35 \%)$. Essa escassez de produção acerca de esportes de inverno nos países que falam e publicam em língua portuguesa é, provavelmente, fruto das condições climáticas destas nações e da consequente falta de envolvimento de indivíduos destes países na prática regular destas modalidades.

Dentre as 2.000 referências relativas às modalidades de verão, $1.956(97,8 \%)$ são relativas ao quadro olímpico e $52(2,6 \%)$ ao paralímpico. Os números acima revelam 
um interessante paradoxo: enquanto a produção científica sobre o esporte paralímpico é ínfima, quando comparada a dos esportes olímpicos, de forma geral o Brasil tem se saído significativamente melhor nos esportes paralímpicos do que nos olímpicos em grandes competições internacionais. Por exemplo, nos últimos três Jogos Olímpicos (2004, 2008 e 2012), o Brasil ficou respectivamente nas seguintes colocações: 16ํㅜ $23^{\circ}$ e 22ํ․ Já nos Jogos

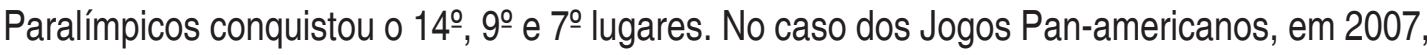
2011 e 2015, o país ficou em terceiro lugar em todas estas ocasiões. Por sua vez, nos Jogos Parapan-americanos, conquistou o primeiro lugar nas três edições.

Esses resultados revelam que a produção científica em português relacionada com 0 esporte paralímpico não acompanha o desenvolvimento e/ou fomenta o desenvolvimento desse tipo de esporte no Brasil. Faz-se interessante lembrar que, de acordo com De Bosscher et al. (2009), um dos fatores de sucesso do esporte de rendimento é a relação que ele estabelece com a produção científica. Esta regra aparentemente não tem se aplicado ao esporte paralímpico brasileiro.

Uma provável causa da escassez de produção acerca do esporte paralímpico é que este é um fenômeno relativamente recente. Ele só começou a tomar corpo a partir da Segunda Guerra, quando passou a ser utilizado como meio de reabilitação e socialização de soldados feridos. Outra provável causa da pouca produção sobre este tipo de esporte é o seu baixo status. Esta condição é visível em vários âmbitos como, por exemplo, no da mídia. Bruce (2014), ao realizar uma extensa revisão de literatura sobre a temática, indicou que a cobertura dos Jogos Paralímpicos na mídia impressa e televisiva tende a ser significativamente menor do que a dos Jogos Olímpicos. De acordo com a autora, as coberturas midiáticas das competições paralímpicas são normalmente de 20 a 200 vezes menores do que a dos Jogos Olímpicos.

A produção referente às diferentes modalidades olímpicas de verão está representada no Gráfico 1.

Gráfico 1 - Artigos relacionados com as modalidades olímpicas de verão

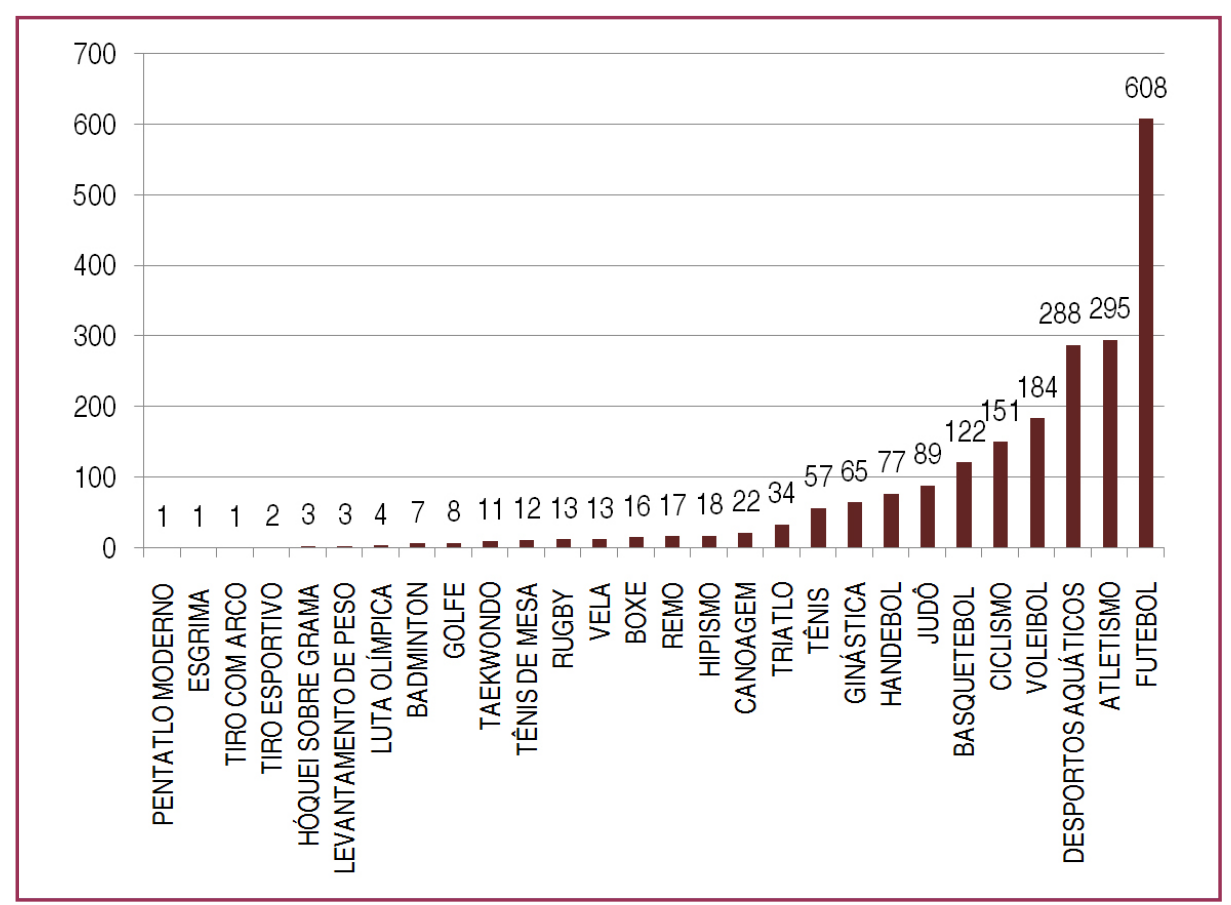

Fonte: Biblioteca Virtual da Saúde (2015); Portal Scielo (2015); e Portal de Periódicos da Capes (2015). Sistematizados pelos autores. 
Conforme mostra o Gráfico 1, as modalidades que possuem os maiores níveis de produção são: futebol $(28,65 \%)$; atletismo (13,9\%); desportos aquáticos (13,57\%); voleibol (8,67\%); ciclismo (7,12\%); basquetebol (5,75\%); judô (4,19\%); handebol $(3,63 \%)$; ginástica $(3,06 \%)$. Outros esportes contam com uma produção escassa, a exemplo do pentatlo moderno $(0,05 \%)$; esgrima $(0,05 \%)$; e tiro com arco $(0,05 \%)$. O pentatlo moderno torna-se um caso interessante, visto que o Brasil hoje tem a atleta Yane Marques, considerada uma das melhores do mundo, que inclusive conquistou a medalha de bronze nas Olimpíadas de Londres em 2012, além de ter subido ao pódio nas duas últimas edições de campeonatos mundiais. Neste caso parece que a produção científica em português não está dando amparo ao desenvolvimento esportivo dos atletas de rendimento dessa modalidade.

O futebol, com $28,65 \%$ da produção, possui um número maior de artigos em relação às outras modalidades. Esse fato não surpreende, considerando que ele é o principal esporte tanto no Brasil como em Portugal. Em ambos os países, o futebol atrai significativo número de praticantes e espectadores. No caso do Brasil, mais especificamente, de acordo com 0 Diagnóstico Nacional do Esporte (MINISTÉRIO DO ESPORTE, 2015), dentro do universo daqueles que praticam algum tipo de atividade esportiva, 42,7\% se envolvem com o futebol, seguido por caminhada, $(8,4 \%)$, voleibol $(8,2 \%)$, academia $(5,1 \%)$, natação $(4,9 \%)$, corrida $(4,1 \%)$, futsal $(3,4 \%)$, musculação $(3,2 \%)$, ciclismo $(2,9 \%)$, handebol $(1,6 \%)$, ginástica $(1,5 \%)$ e basquetebol (1,5\%). Ao considerar a lista dos mais praticados de acordo com o Diagnóstico, retirando os que não se configuram enquanto modalidades olímpicas e paralímpicas, verificase que os mais praticados depois do futebol são o voleibol, a natação e a corrida (esta, por sua vez, é somente uma especialidade do atletismo). Nota-se que estas são as modalidades que também mais possuem produção científica em língua portuguesa.

A produção em relação às modalidades paralímpicas de verão pode ser observada no gráfico abaixo:

Gráfico 2 - Artigos sobre modalidades paralímpicas de verão

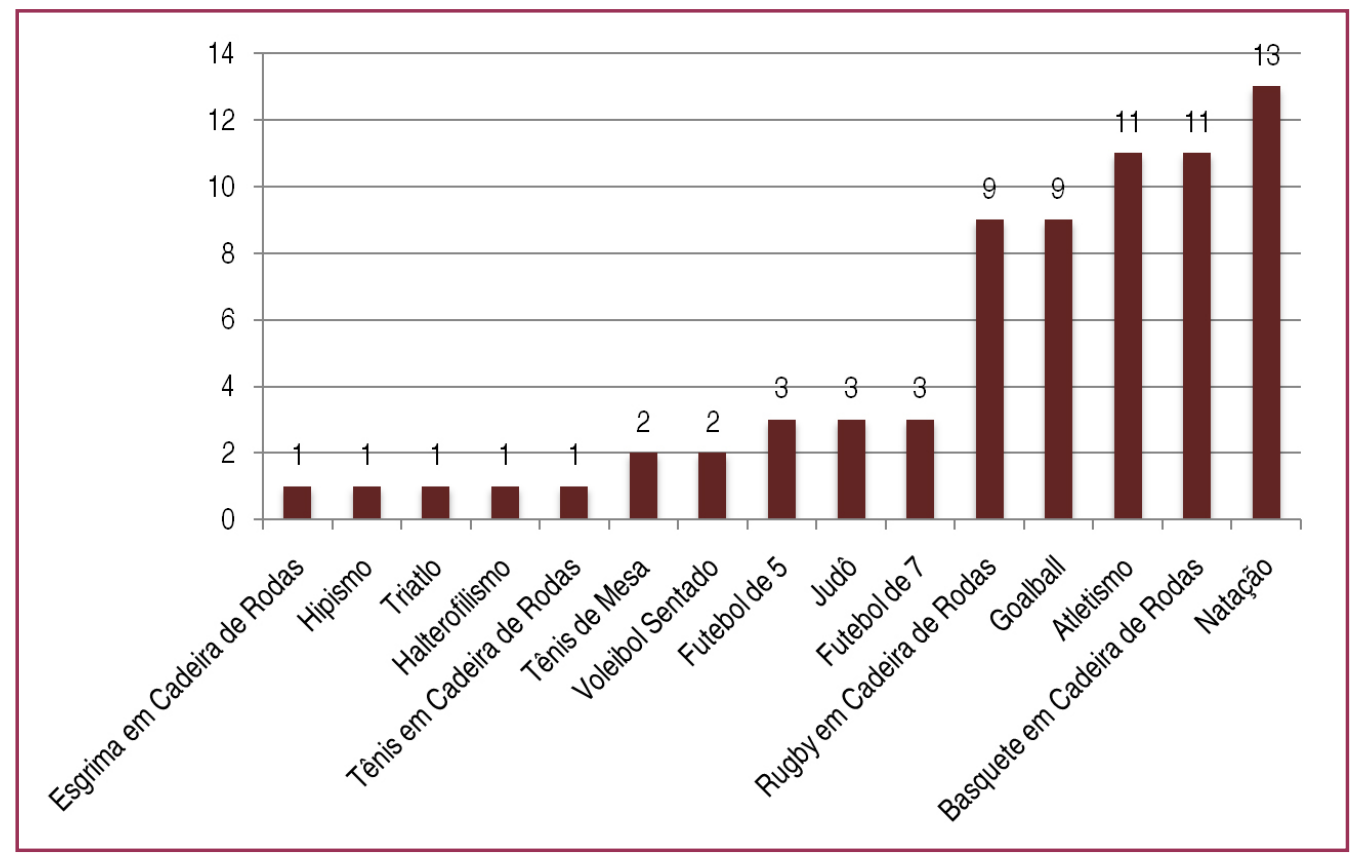

Fonte: Biblioteca Virtual da Saúde (2015); Portal Scielo (2015); e Portal de Periódicos da Capes (2015). Sistematizado pelos autores. 
Dentre a pequena produção relativa às modalidades paralímpicas de verão, a que mais se destaca é a natação, seguida do basquete em cadeira de rodas, atletismo, goalball e o rúgbi em cadeira de rodas. No outro extremo, com um único artigo publicado, estão a esgrima em cadeira de rodas, hipismo, triatlo, halterofilismo e tênis em cadeira de rodas.

Em relação à produção relativa às modalidades olímpicas de inverno (seis artigos), destacam-se o esqui, com três trabalhos, seguido de patinação, com dois, e hóquei no gelo, com um. Foi encontrado apenas um artigo relacionado com modalidades paralímpicas de inverno e este se refere ao esqui alpino.

Quanto ao enfoque temático dos artigos referentes às modalidades olímpicas de verão, prevalecem as seguintes categorias: treinamento (31,7\%), saúde (18,36\%) e iniciação esportiva e categorias de base $(14,15 \%)$ :

Gráfico 3 - Enfoques Temáticos das modalidades olímpicas de verão

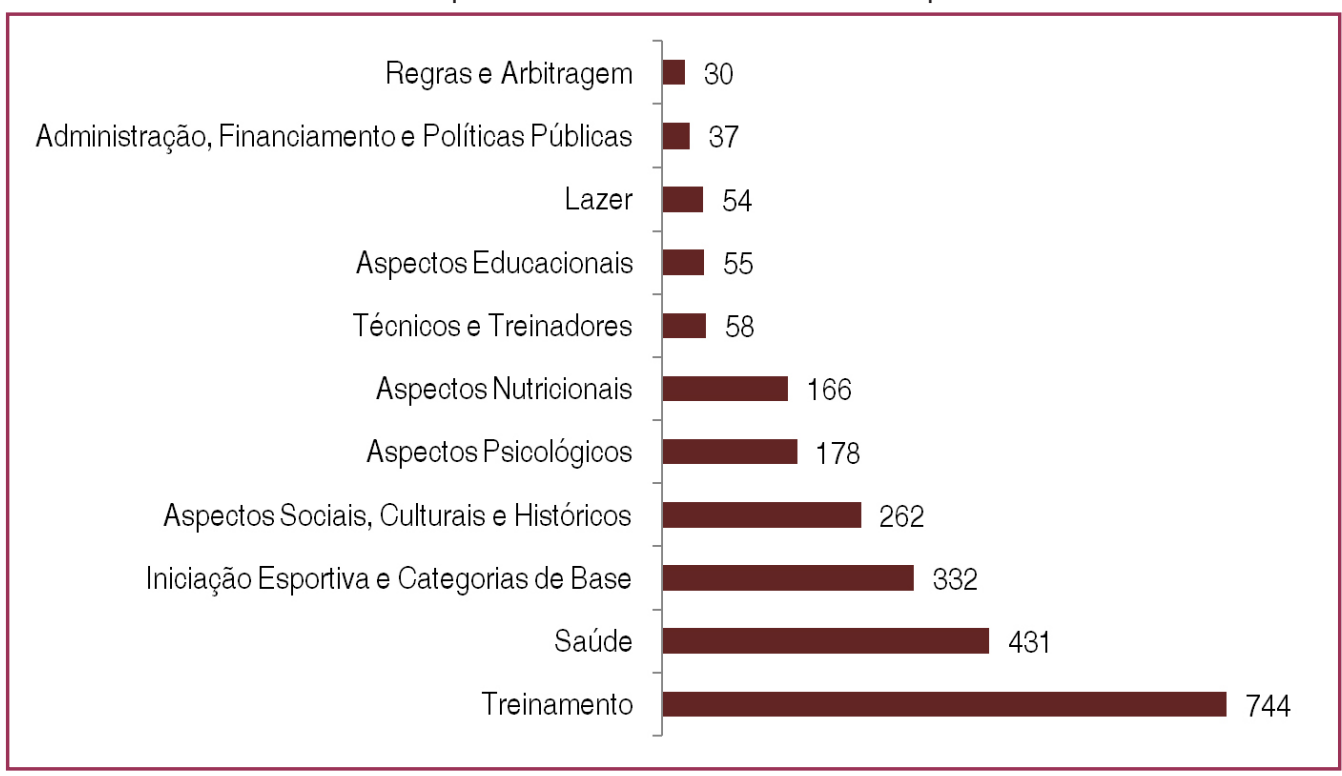

Fonte: Biblioteca Virtual da Saúde (2015); Portal Scielo (2015); e Portal de Periódicos da Capes (2015). Sistematizado pelos autores.

As categorias "treinamento" e "saúde" também predominam no esporte paralímpico:

Gráfico 4 - Enfoques Temáticos modalidades paralímpicas de verão

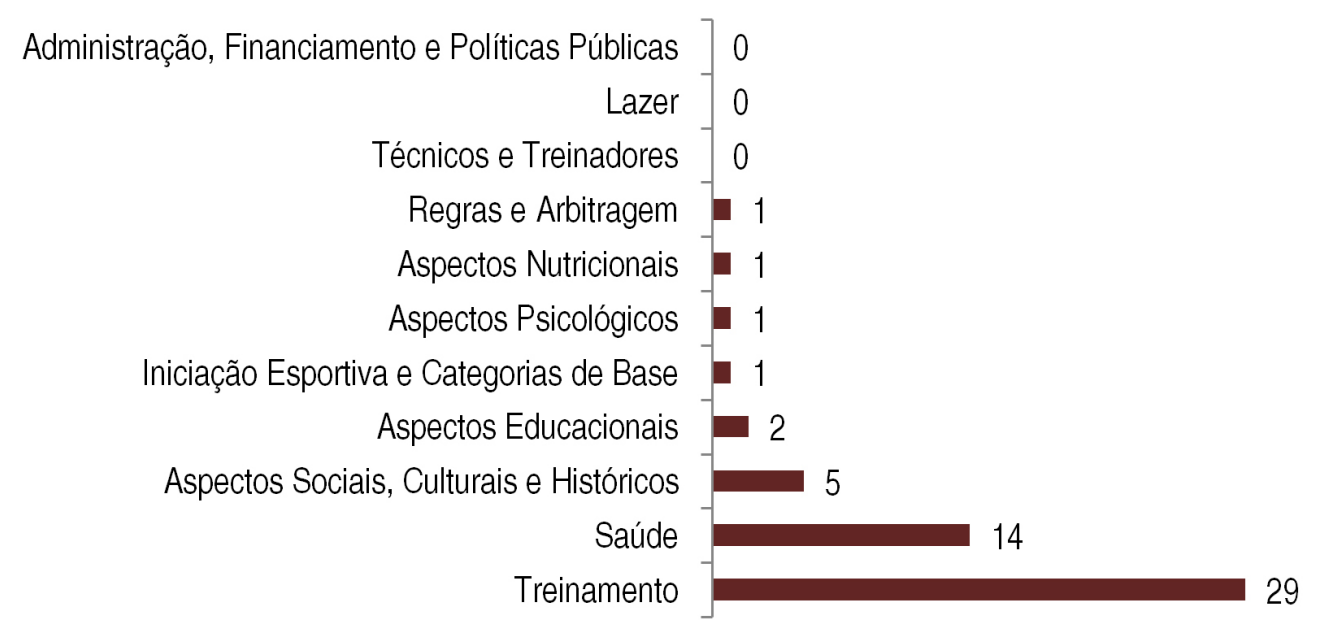

Fonte: Biblioteca Virtual da Saúde (2015); Portal Scielo (2015); e Portal de Periódicos da Capes (2015). - Sistematizado pelos autores. 
A Tabela 1 apresenta os dados sobre o número de artigos referentes às modalidades olímpicas de verão:

Tabela 1 - Número de artigos referentes às modalidades olímpicas de verão.

\begin{tabular}{|c|c|c|c|c|c|c|c|c|c|c|c|}
\hline $\begin{array}{l}\frac{0}{8} \\
\frac{\pi}{0} \\
\frac{0}{0} \\
\frac{\pi}{0} \\
\sum\end{array}$ & 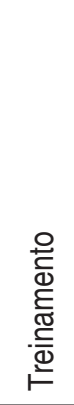 & 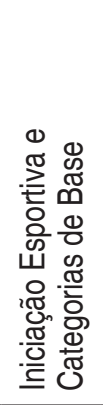 & $\begin{array}{l}\frac{0}{0} \\
\text { 心 } \\
\text { ஸ }\end{array}$ & 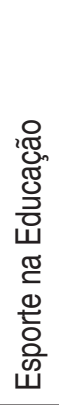 & 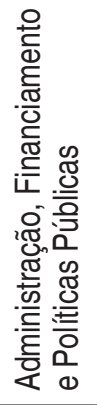 & $\begin{array}{l}\bar{\Phi} \\
\text { త్త }\end{array}$ & 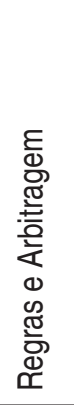 & 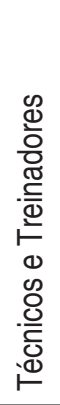 & 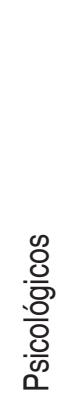 & 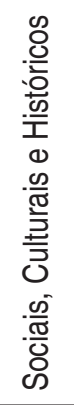 & 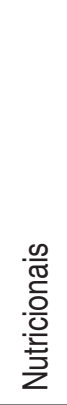 \\
\hline Total Geral & 788 & 374 & 462 & 64 & 37 & 60 & 41 & 60 & 221 & 276 & 190 \\
\hline Futebol & 186 & 121 & 75 & 20 & 25 & 15 & 26 & 18 & 51 & 188 & 24 \\
\hline Atletismo & 139 & 31 & 82 & 15 & 0 & 15 & 4 & 1 & 19 & 13 & 32 \\
\hline Desportos Aquáticos & 120 & 31 & 90 & 4 & 1 & 2 & 2 & 1 & 23 & 3 & 35 \\
\hline Voleibol & 53 & 50 & 34 & 4 & 2 & 3 & 1 & 11 & 37 & 12 & 9 \\
\hline Ciclismo & 63 & 2 & 63 & 3 & 3 & 17 & 1 & 1 & 2 & 3 & 25 \\
\hline Basquetebol & 36 & 36 & 23 & 5 & 3 & 1 & 1 & 10 & 23 & 6 & 7 \\
\hline Judô & 36 & 17 & 25 & 2 & 0 & 0 & 1 & 6 & 18 & 8 & 15 \\
\hline Ginástica & 18 & 28 & 14 & 4 & 1 & 0 & 2 & 7 & 11 & 6 & 16 \\
\hline Handebol & 27 & 22 & 13 & 5 & 0 & 0 & 0 & 4 & 13 & 3 & 6 \\
\hline Tênis & 18 & 21 & 15 & 0 & 0 & 2 & 0 & 1 & 10 & 1 & 5 \\
\hline Triatlo & 32 & 0 & 3 & 0 & 0 & 0 & 0 & 0 & 2 & 1 & 7 \\
\hline Canoagem & 13 & 2 & 5 & 1 & 2 & 2 & 0 & 0 & 2 & 0 & 0 \\
\hline Hipismo & 8 & 0 & 2 & 0 & 0 & 1 & 1 & 0 & 0 & 6 & 1 \\
\hline Remo & 9 & 0 & 1 & 0 & 0 & 1 & 0 & 0 & 0 & 6 & 1 \\
\hline Boxe & 1 & 0 & 4 & 0 & 0 & 0 & 1 & 0 & 1 & 8 & 1 \\
\hline Rugby & 9 & 0 & 2 & 0 & 0 & 0 & 0 & 0 & 0 & 2 & 0 \\
\hline Vela & 3 & 1 & 2 & 0 & 0 & 1 & 0 & 0 & 6 & 0 & 0 \\
\hline Taekwondo & 2 & 2 & 2 & 0 & 0 & 0 & 0 & 0 & 1 & 4 & 2 \\
\hline Tênis de Mesa & 6 & 3 & 1 & 0 & 0 & 0 & 1 & 0 & 1 & 0 & 0 \\
\hline Golfe & 1 & 3 & 1 & 0 & 0 & 0 & 0 & 0 & 0 & 3 & 1 \\
\hline Badminton & 3 & 2 & 1 & 0 & 0 & 0 & 0 & 0 & 0 & 1 & 0 \\
\hline Luta Olímpica & 1 & 0 & 2 & 0 & 0 & 0 & 0 & 0 & 0 & 1 & 1 \\
\hline Hoquei sobre a grama & 1 & 0 & 0 & 0 & 0 & 0 & 0 & 0 & 1 & 1 & 1 \\
\hline Levantamento de peso & 1 & 0 & 1 & 0 & 0 & 0 & 0 & 0 & 0 & 0 & 1 \\
\hline Tiro Esportivo & 1 & 0 & 1 & 0 & 0 & 0 & 0 & 0 & 0 & 0 & 0 \\
\hline Esgrima & 0 & 1 & 0 & 1 & 0 & 0 & 0 & 0 & 0 & 0 & 0 \\
\hline Tiro com Arco & 1 & 0 & 0 & 0 & 0 & 0 & 0 & 0 & 0 & 0 & 0 \\
\hline Pentatlo Moderno & 0 & 1 & 0 & 0 & 0 & 0 & 0 & 0 & 0 & 0 & 0 \\
\hline
\end{tabular}

Fonte: Biblioteca Virtual da Saúde (2015); Portal Scielo (2015); e Portal de Periódicos da Capes (2015).

Conforme observado, a maior parte dos artigos referentes a cada modalidade esportiva teve como principal enfoque os aspectos relacionados ao treinamento, exceto em alguns poucos casos. A respeito do futebol, por exemplo, dos 749 artigos, 188 enfocam aspectos sociais, culturais e históricos seguidos de 186 que se centram na temática do treinamento. Não 
se pode desconsiderar o espaço diferenciado que o futebol ocupa como objeto de estudo na área sociocultural dentro da Educação Física e/ou nas Ciências Humanas, o que não ocorre com a maior parte das outras modalidades. No caso dos esportes paralímpicos de verão, as temáticas "treinamento" e "saúde" também são predominantes. Do total de 52 artigos, 29 se encaixam na primeira categoria e 14 na segunda. Aponta-se que não foi realizada uma análise da predominânica dos principais enfoques temáticos de modalidades de inverno, pois esta ficaria enviesada considerando o baixo número de artigos.

Outra intenção foi verificar quem são os autores e quais os principais centros de produção. Dentre os 3.531 autores dos artigos que possuem currículo Lattes e/ou DeGóis disponível, praticamente a metade (47,84\%) possui o título de doutor e $17,79 \%$ são mestres. Uma parcela significativa do restante dos autores estava com o mestrado e/ou doutorado em andamento (16,88\%). Tais números mostram, conforme apontam Pereira da Silva, GonçalvesSilva e Moreira (2014), que a produção de artigos científicos está bastante vinculada aos programas de pós-graduação strictu sensu.

Os autores que mais produziram sobre as modalidades esportivas são todos brasileiros: Francisco Navarro (UFMA), com 38 artigos, Benedito Sérgio Denadai (UNESP), 37; Luiz Guilherme Guglielmo (UFSC), 27; Cláudio Alexandre Gobatto (UNICAMP), 25; Fábio Yuzo Nakamura (UEL), 25; Pablo Juan Greco (UFMG), 22; Saray Giovana dos Santos (UFSC), 22. Todos esses autores têm título de doutor e estão credenciados em algum programa de pós-graduação. Outro fato interessante é que, com exceção de Francisco Navarro, todos os outros estão lotados em universidades do sul e do sudeste do Brasil, mostrando, assim, como apontam Manoel e Carvalho (2011), como os programas e a produção do conhecimento na área de Educação Física estão centrados nessas regiões.

Do total de 653 instituições, a maioria dos pesquisadores é vinculada às universidades públicas brasileiras. As três mais produtivas são do estado de São Paulo:

Tabela 2 - Instituições com maior produção.

\begin{tabular}{ccc}
\hline Instituições & Artigos Publicados & $\%$ \\
\hline Universidade de São Paulo & 259 & $7,08 \%$ \\
Universidade Estadual Paulista “Júlio de Mesquita Filho" & 194 & $5,30 \%$ \\
Universidade Estadual de Campinas & 149 & $4,07 \%$ \\
Universidade Gama Filho & 146 & $3,99 \%$ \\
Universidade Federal do Rio Grande do Sul & 130 & $3,55 \%$ \\
Universidade Federal de Santa Catarina & 117 & $3,20 \%$ \\
Universidade Estadual de Londrina & 102 & $2,79 \%$ \\
Universidade do Porto - Portugal & 86 & $2,35 \%$ \\
Universidade Federal de Minas Gerais & 82 & $2,24 \%$ \\
Universidade Federal de São Paulo & 75 & $2,05 \%$ \\
Universidade Federal do Rio de Janeiro & 74 & $2,02 \%$ \\
Universidade do Estado de Santa Catarina & 65 & $1,78 \%$ \\
Universidade Federal do Paraná & 65 & $1,78 \%$ \\
Universidade Estadual de Maringá & 52 & $1,42 \%$ \\
Universidade Federal de Viçosa & 49 & $1,34 \%$ \\
\hline
\end{tabular}

Fonte: Biblioteca Virtual da Saúde (2015); Portal Scielo (2015); Portal de Periódicos da Capes (2015); Plataforma Lattes (2015) e Plataforma DeGóis (2015). Sistematizada pelos autores. 
Como pode ser verificado acima, a USP aparece com o maior número de artigos na produção sobre modalidades esportivas olímpicas e paralímpicas, corroborando o papel protagonista que a instituição exerce na área de Educação Física, sinalizado por Rosa e Leta (2011). Em seguida aparecem a UNESP, UNICAMP e UGF. Salienta-se que praticamente todas as instituições presentes na tabela acima estão localizadas nas regiões Sul e Sudeste do Brasil, são universidades públicas e têm programas de pós-graduação em Educação Física. A única universidade privada é a UGF. Esta, no entanto, recentemente fechou seus cursos de mestrado e doutorado e, por conta disso, provavelmente tende a ter sua produtividade diminuída em anos futuros. O papel protagonista da USP, UNESP e UNICAMP na produção na área é de certa forma esperado, visto que, conforme aponta Cruz (2010), essas instituições também lideram esse quadro em diversas outras áreas do conhecimento.

Outro ponto a ser mencionado é que o Programa de Pós-Graduação em Educação Física da USP é o único a ter o conceito 7, o máximo que pode ser obtido no atual sistema de avaliação da Capes. Seguido pelo da UNESP, que possui o segundo maior conceito, a nota 6 . As outras instituições possuem programas com notas que variam de 3 a 5 . Vale ressaltar que a Universidade do Porto é a única instituição não brasileira que figura entre as mais produtivas. Essa universidade portuguesa tem uma larga tradição em pesquisas sobre o esporte, tendo, inclusive, formado vários mestres e doutores brasileiros.

\subsection{A diversidade epistemológica do fazer ciência em esporte}

Foi realizado um levantamento sobre as áreas de formação em nível de graduação dos autores. Foram encontrados 3.531 autores cujos currículos Lattes e/ou DeGóis estavam disponíveis online. Os outros 1.029 autores, ou seja, aproximadamente $23 \%$, não possuíam o currículo disponível durante o período da coleta de dados. Os resultados deste levantamento são os seguintes:

Gráfico 5 - Número de autores por áreas de graduação

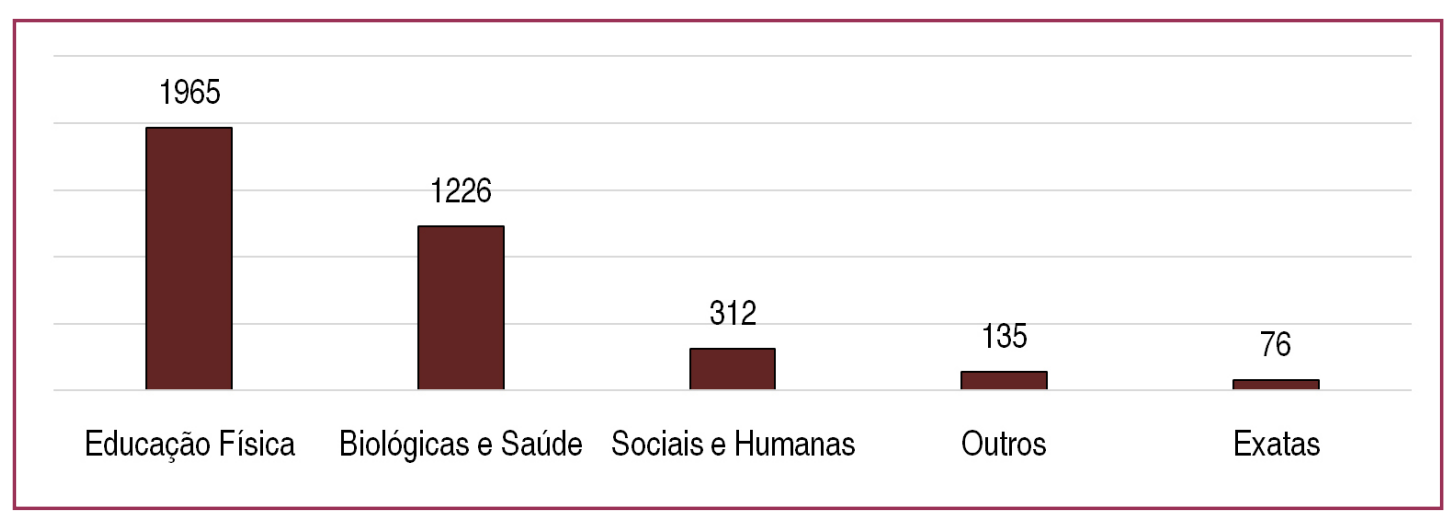

Fonte: Plataforma Lattes (2015) e Plataforma DeGóis (2015). Sistematizado pelos autores.

A maior parte dos autores (1965) possui formação em Educação Física e/ou área correlata. A segunda área que mais possui autores é a "Biológicas e Saúde" (1226), que agrega pesquisadores formados em Fisioterapia, Medicina, Nutrição, Farmácia e Bioquímica, Ciências Biológicas, entre outras. Do total de 312 autores que publicaram na categoria "Sociais e

1114 
Humanas", as áreas que mais apareceram foram Psicologia, Pedagogia, Direito, Administração e Ciências Sociais. No caso da categoria "Ciências Exatas", com 76 artigos, destacam-se as engenharias e áreas tecnológicas, tais como desenvolvimento de software, sistemas de informação, tecnologia em processamento de dados, tecnologia em radiologia. Já a categoria "outros" agregou áreas como Turismo, Agronomia e Ciências Militares.

Apesar de ocorrer uma predominância de autores com graduações em Educação Física e/ou correlata é possível perceber a diversidade de formações existentes entre aqueles que estão publicando sobre o esporte. Essa variedade ocorre porque, além de estudiosos da Educação Física transitarem por áreas distintas, também existem pesquisadores de outras esferas estudando questões relacionadas ao esporte. Tal fato reforça a variedade epistemológica existente na área da Educação Física no Brasil (RIGO; RIBEIRO; HALLAL, 2011; LAZZAROTTI FILHO et al. 2012; TANI, 2014).

Optou-se por manter a Educação Física de forma separada das grandes áreas de conhecimento por ser ela a formação que, mesmo sozinha, mais produz sobre o esporte em língua portuguesa. Esta opção também aconteceu em virtude, conforme lembram Lazzarotti Filho et al. (2012), do grande debate epistemológico existente na área. Enquanto alguns a classificam como parte das Ciências Naturais ou, conforme classificação da Capes, da grande área da saúde, outros a percebem como sendo mais próxima das Ciências Humanas.

Autores como Manoel e Carvalho (2011), Rigo, Ribeiro e Hallal (2011) e Pereira da Silva, Gonçalves-Silva e Moreira (2014) afirmam que a produção científica da área da Educação Física sofre forte influência do sistema de avaliação dos programas de pósgraduação regido pela Capes. Tal organismo enquadra a Educação Física no campo da saúde e, mais especificamente, na "área 21", que além da Educação Física abriga também a Fisioterapia, Fonoaudiologia e a Terapia Ocupacional. Ocorre que o principal critério de avaliação dos programas por esta instituição são as publicações com alto fator de impacto que, consequentemente, são os periódicos melhor avaliados no sistema "Qualis periódico" (RIGO; RIBEIRO; HALLAL, 2011). Este sistema, por sua vez, estratifica as revistas tomando como base 0 seu fator de impacto e as bases de dados em que as publicações estão indexadas.

Rigo, Ribeiro e Hallal (2011), ao realizarem estudos sobre o Qualis periódico da área 21, verificaram que existe uma oferta maior de periódicos melhor estratificados voltados para as Ciências Naturais. Em um levantamento realizado em agosto de 2014 no Qualis periódico, Manoel (2015) constatou que 70\% dos periódicos no extrato A1 são da Medicina e Ciências Biológicas. $O$ autor também constatou que nos três principais extratos dos periódicos $A 1, A 2$ e B1 há um predomínio de revistas situadas nos aspectos biodinâmicos em detrimento dos aspectos sociais e humanos. Essa constatação do autor é, de certa forma, previsível. Afinal, devido à tradição epistemológica da área da Educação Física ser mais próxima das Ciências Naturais, é de se esperar que mais periódicos destas áreas sejam superiores em número em relação às publicações das Ciências Humanas, pois o número de pesquisadores também é maior.

Sobre essa temática, Pereira da Silva, Gonçalves-Silva e Moreira (2014) chamam a atenção para o fato de os pesquisadores da Educação Física no Brasil estarem predispostos a optar por temáticas mais propensas a serem publicadas em revistas de impacto. Os autores também apontam que a quantidade de revistas inclinadas a publicar artigos com abordagem das humanidades é menor do que das Ciências Naturais. 
A realidade dos programas de pós-graduação em Educação Física certamente exerce profundas influências no perfil, bem como nas condições de produção do conhecimento científico disponível sobre o esporte. Este fato determina a preponderância de determinados objetos e abordagens epistemológicas no fazer ciência da área. Vale lembrar ainda que a tradição de pesquisa e as condições de produção da área 21 também têm forte influência nas abordagens epistemológicas que permeiam a Educação Física desde a década de 1980.

Essas questões se materializam nos artigos catalogados para esta pesquisa. Do total de 2.007 artigos, 1.565 são de cunho quantitativo (78\% da produção), 373 qualitativo (19\%), e $69(3 \%)$ quanti-qualitativo. Esse perfil da produção condiz com o escopo dos periódicos que mais têm publicado artigos em português: Revista Brasileira de Medicina do Esporte (A2), com 354 artigos, seguida da Revista Brasileira de Educação Física e Esporte (B1-160), Revista Brasileira de Cineantropometria (B1-138), Revista Brasileira de Ciência e Movimento (B2-116), Motriz (B1-113) e Revista Brasileira de Futsal e Futebol (B5-108).

Tabela 3 - Escopo dos periódicos.

\begin{tabular}{cc}
\hline Periódicos & Escopo \\
\hline Motriz (B1) & $\begin{array}{c}\text { Pesquisas originais em Ciências do Movimento } \\
\text { Humano e áreas relacionadas com o desporto e } \\
\text { exercício físico }\end{array}$ \\
\hline Revista Brasileira de Ciência e Movimento (B2) & Áreas da atividade física, do exercício e do esporte \\
Revista Brasileira de Cineantropometria e & $\begin{array}{c}\text { Ciência do movimento humano, com ênfase na } \\
\text { cineantropometria nas suas vertentes morfológica e } \\
\text { funcional, bem como os fatores condicionantes do } \\
\text { desempenho físico }\end{array}$ \\
\hline Revista Brasileira de Educação Física e Esporte (B1) & $\begin{array}{c}\text { Áreas de Educação Física, Esporte e afins } \\
\text { Revista Brasileira de Futsal e Futebol (B5) }\end{array}$ \\
$\begin{array}{c}\text { O Futsal, o Futebol e a Pedagogia do Esporte no } \\
\text { sentido da aprendizagem, da iniciação e do alto } \\
\text { rendimento no âmbito do esporte, da educação e da } \\
\text { sociedade. }\end{array}$ \\
\hline Revista Brasileira de Medicina do Esporte (A2)
\end{tabular}

Fonte: Qualis (2014). Sistematizado pelos autores

No que se refere aos escopos dos periódicos que mais artigos publicaram sobre esporte em língua portuguesa, observa-se que todos possuem, conforme lembra Tani (2014), uma identidade inequívoca com a Educação Física. Dentre os periódicos de grande aderência, encontram-se os de escopo específico, como a Revista Brasileira de Medicina do Esporte e a Revista Brasileira de Cineantropometria, que possuem uma maior afinidade epistemológica com as Ciências Naturais. Os outros quatro periódicos possuem linhas editoriais mais amplas, aceitando submissões das mais variadas orientações epistemológicas. Contudo, apesar de terem um escopo abrangente e publicarem frequentemente estudos nas humanidades, vinculam em suas páginas mais artigos amparados num referencial das Ciências Naturais.

Para finalizar, cabe esclarecer que se discutiu em mais detalhe as condições de produção do conhecimento da Educação Física no Brasil, considerando que a maioria a dos autores e revistas científicas que publicam sobre o esporte em português está vinculada às instituições brasileiras com programas de pós-graduação em Educação Física. 
Gráfico 6 - Número de artigos por ano de publicação

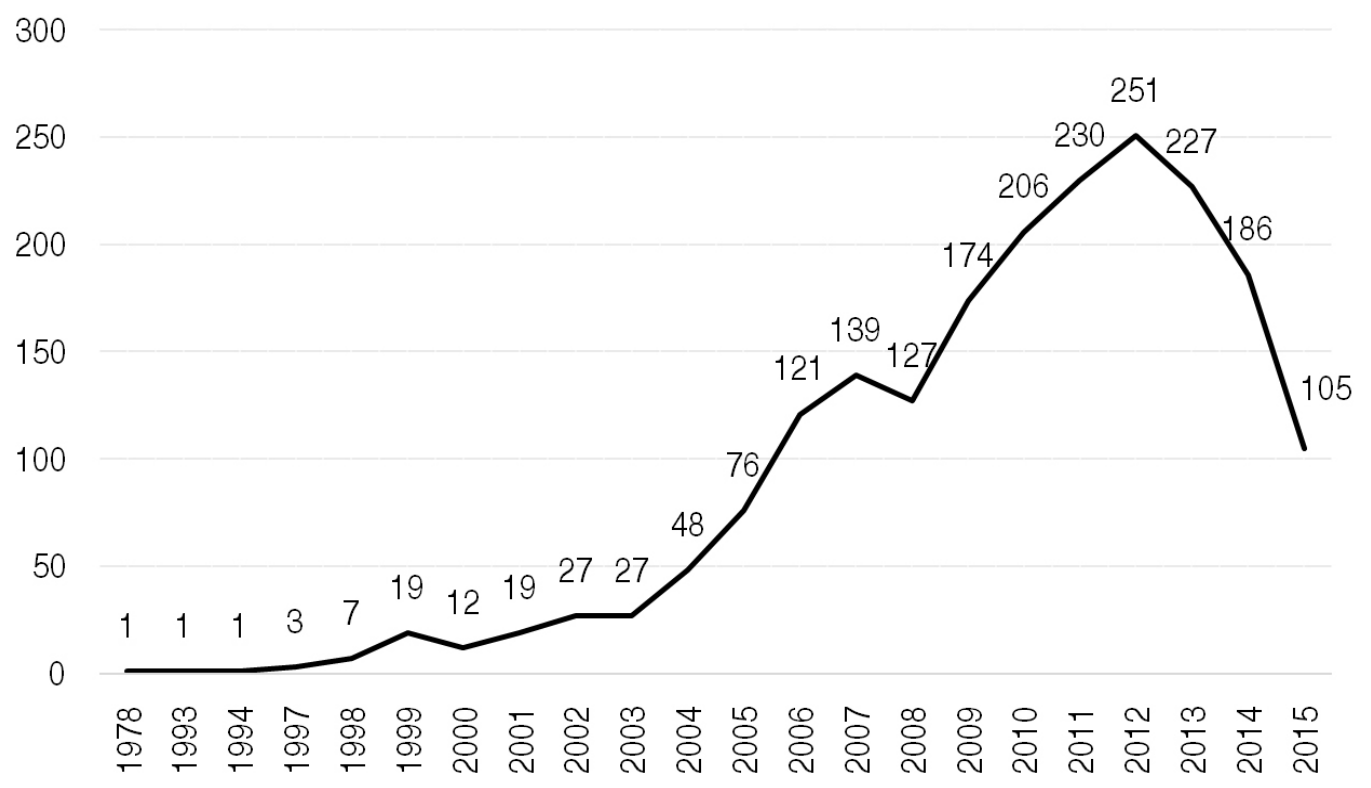

Fonte: Biblioteca Virtual da Saúde (2015); Portal Scielo (2015); e Portal de Periódicos da Capes (2015). Sistematizado pelos autores.

Ressalta-se que a queda abrupta na produção em anos mais recentes que aparece no gráfico acima talvez não seja real, uma vez que se coletaram os dados em dezembro de 2015. Sabe-se que algumas edições de anos anteriores saem com atraso e, em alguns casos, não são indexadas automaticamente em bases de dados.

0 aumento da produção científica nas diferentes áreas do conhecimento, incluindo sobre o esporte, está relacionado, muito provavelmente, com fatores como o crescimento no número de programas de pós-graduação no Brasil, políticas de indução de produção de conhecimento e maior aporte financeiro para financiamento de pesquisas, exigência de publicação de artigos para credenciamento e sua manutenção, e de pesquisadores em programas de pós-graduação (PEREIRA DA SILVA; GONÇALVES-SILVA; MOREIRA, 2014). RIGO; RIBEIRO; HALLAL (2011), por exemplo, fizeram um levantamento sobre o crescimento dos programas de Educação Física. De acordo com os autores, em 1980 o país contava com apenas dois programas de mestrado. De acordo com a coordenação da área 21 da Capes, atualmente existem 32 programas com mestrados e 20 doutorados (CAPES, 2016).

Diante dos dados sobre o aumento da produção científica sobre o esporte, indaga-se se os conhecimentos que têm sido produzidos têm se endereçado de fato às necessidades de profissionais da área e se têm sido apropriados por estes. Nessa linha argumentativa, Nakamura (2015) afirma que as pressões exercidas por pares, órgãos de fomento de pesquisa e pelo sistema de avaliação da pós-graduação no Brasil, que impõem curtos prazos para a produção e publicação de trabalhos, têm fomentado uma lógica prejudicial ao desenvolvimento do esporte no país. De acordo com o autor, existe uma predominância de pesquisas descritivas e de corte transversal em detrimento de pesquisas de intervenção, do tipo experimental e/ou longitudinal, uma vez que as primeiras podem ser produzidas com mais rapidez que as últimas. Conforme 0 autor, as características da produção de conhecimentos sobre o treinamento esportivo atualmente têm servido mais à própria academia - e aos pesquisadores que os produzem - do que aos profissionais que trabalham com o esporte, como treinadores e preparadores físicos. 


\section{CONSIDERAÇÕES FINAIS}

Uma das limitações do presente estudo é que os dados aqui apresentados se referem apenas a artigos escritos em português. Diante da internacionalização da produção, que se faz cada vez mais presente e contundente na área da Educação Física (TANI, 2014), caso haja a intenção de se estudar o que os pesquisadores que vivem em países que falam 0 português têm produzido sobre o esporte, são necessárias novas pesquisas que levantem estudos também em outras línguas, sobretudo em inglês.

Esta pesquisa evidencia que a produção científica relacionada com 0 esporte privilegia as modalidades olímpicas de verão. Ela demonstra também que a produção sobre o esporte paralímpico de verão é ainda incipiente e que não existe praticamente nada sobre modalidades olímpicas e paralímpicas de inverno. Este estudo ainda indica que, enquanto algumas modalidades, como o futebol, os esportes aquáticos e 0 atletismo, possuem uma produção significativa, outras, como o pentatlo moderno e a esgrima, possuem apenas um artigo publicado.

O treinamento apareceu como eixo temático com maior número de estudos publicados. Uma ressalva merece ser feita, no entanto: apesar de os artigos sobre treinamento terem sido os preponderantes, não se pode considerar esta produção abrangente, visto que 0 número apresentado de 773 artigos é pequeno para representar toda a pesquisa cientíica sobre esporte em língua portuguesa. Afinal, como aponta Nakamura (2015), a pesquisa em treinamento esportivo no Brasil, apesar de ter pesquisadores qualificados e com boa inserção internacional, ainda se encontra em fase incipiente.

No que se refere aos centros de produção destes artigos, a USP aparece como a instituição com o maior número de manuscritos publicados, seguindo a tendência apontada por Rosa e Leta (2011). Outras universidades paulistas, como a UNESP e a UNICAMP também se destacam. Como visto, as regiões Sudeste e Sul são as que possuem o maior número de instituições que estão produzindo sobre as modalidades olímpicas e paralímpicas, o que pode ser explicado pelo fato, conforme apontam Manoel e Carvalho (2011), de os programas de pósgraduação em Educação Física estarem concentrados nestas localidades.

O Reino Unido, por exemplo, tem buscado soluções para diminuir o visível distanciamento existente entre a produção científica e a sua aplicação na sociedade de forma mais geral. A partir de 2014, foi implementada uma nova forma de avaliação das universidades a qual foi denominada de Research Excellence Framework (REF2014, 2011). De acordo com as novas normas, $20 \%$ das notas atribuídas às instituições baseiam-se no alcance e na proporção do impacto das pesquisas produzidas na economia, sociedade e cultura, bem como na abordagem das instituições de ensino superior na promoção de impactos nessas esferas a partir das pesquisas produzidas em seu interior. Sujeitas a essa nova forma de avaliação, as universidades estão incentivando os seus docentes a produzirem dentro dessa nova lógica. Também os pesquisadores, em busca de recursos para os seus estudos, passaram a priorizar pesquisas que possam de alguma forma diretamente contribuir para melhorias na economia, sociedade e/ou cultura. Talvez a saída para os países de língua portuguesa, sobretudo no caso do Brasil, seria a instituição de Mestrados Profissionais na área do Esporte, visto que eles poderiam contribuir na diminuição do abismo encontrado entre a esfera científica e a atuação dos indivíduos envolvidos com o dia a dia do esporte. 
Nesse sentido, este estudo oferece subsídios para ampliar o entendimento sobre 0 atual quadro da produção do conhecimento acerca do esporte. Os dados apresentados, bem como a compreensão deles, podem contribuir para o fomento de conhecimentos em áreas mais necessitadas e estratégicas do esporte. Ressalta-se a necessidade de mais estudos no sentido de se entender o fenômeno esportivo em toda a sua complexidade. Necessita-se, também, de mais pesquisas que possam efetivamente contribuir para com o trabalho daqueles que fazem o esporte cotidianamente acontecer.

\section{REFERÊNCIAS}

BENTO, Jorge. Em nome do desporto. In: GAYA, Adroaldo C. A. (Org.) Educação Física: ordem, caos e utopia. Casa da Educação Física: Belo Horizonte, 2014. p.135-178.

BIBLIOTECA VIRTUAL DE SAÚDE. Portal Regional da BVS. Disponível em: < http://bvsalud.org/>. Acesso em: 15 jul. 2015.

BRUCE, Toni. Us and them: the influence of discourses of nationalism on media coverage of the Paralympics. Disability \& Society, v. 29, n. 9, p. 1443-1459, 2014.

CAPES. Cursos Recomendados. Disponível em: < http://www.capes.gov.br/cursos-recomendados $>$. Acesso em: 3 mar. 2016.

CRUZ, Carlos H. B. Ciência, Tecnologia e Inovação no Brasil: desafios para o período 2011 a 2015. Revista Interesse Nacional, v.3, n.10, p. 1-17, 2010.

DE BOSSCHER, Veerle et al. Explaining international sporting success: An international comparison of elite sport systems and policies in six countries. Sport Management Review, v. 12, n. 3, p. 113-136, 2009.

LAZZAROTTI FILHO, Ari et al. Modus operandi da produção científica da EF: uma análise das revistas e suas veiculações. Revista da Educação Física/UEM, v. 23, n. 1, p. 1-14, 2012.

MANOEL, Edison J. Produtivismo e Ética na pesquisa em Educação Física: leituras, um conto e alguns casos. In: RECHIA, Simone et al. (Org.). Dilemas e Desafios da Pós-Graduação em Educação Física. ljuí: Ed. UNIJUİ, 2015. p. 235-281.

MANOEL, Edison J.; CARVALHO, Yara M. Pós-graduação na educação física brasileira: a atração (fatal) para a biodinâmica. Educação e Pesquisa, v. 37, n. 2, p. 389-406, 2011.

MINISTÉRIO DO ESPORTE. Diagnóstico Nacional do Esporte. Brasília, 2015. p. 1-43. (Caderno 1).

NAKAMURA, Fábio Y. A produção do conhecimento acerca do treinamento esportivo no Brasil: análise a partir dos eventos do CBCE e do GPMCE. In: RECHIA, Simone. et al. (Org.). Dilemas e Desafios da Pós-Graduação em Educação Física. Ijuí: Ed. UNIJUİ, 2015. p. 393- 407.

PEREIRA DA SILVA, Junior V.; GONÇALVES-SILVA, LANA L.; MOREIRA, Wagner W. Produtivismo na pós-graduação. Nada é tão ruim, que não possa piorar. É chegada a vez dos orientandos!

Movimento, v. 20, n. 4, p. 1423 - 1445, out./dez. 2014.

PLATAFORMA DE GÓIS. Área investigador. Disponível em: < http://www.degois.pt/globalindex.jsp>. Acesso em: 12 mar. 2016.

PLATAFORMA LATTES. Currículo Lattes. Disponível em: <http://buscatextual.cnpq.br/buscatextual/ busca.do?metodo=apresentar >. Acesso em: 12 mar. 2016. 
PORTAL PERIÓDICOS CAPES. Periódicos. Disponível em: < http://www.periodicos.capes.gov.br/>. Acesso em: 15 jul. 2015.

QUALIS. Periódicos Qualis 2014. Disponível em: < https://sucupira.capes.gov.br/sucupira/public/ consultas/coleta/veiculoPublicacaoQualis/listaConsultaGeralPeriodicos.jsf >. Acesso em: 26 out. 2015.

REF 2014 - Research Excellence Framework. Assessment framework and guidance on submissions. London, 2011. Disponível em: <http://www.ref.ac.uk/media/ref/content/pub/ assessmentframeworkandguidanceonsubmissions/GOS\%20including\%20addendum.pdf > Acesso em: 10 out. 2015

RIGO, Luiz C.; RIBEIRO, Gabriela M. HALLAL, Pedro C. Unidade na diversidade: desafios para a Educação Física no século XXI. Revista Brasileira de Atividade Física \& Saúde, v.16, n.4, p.339345, 2011.

ROSA, Suely; LETA, Jacqueline. Tendências atuais da pesquisa brasileira em Educação Física. Parte 2: a heterogeneidade epistemológica nos programas de pós-graduação. Revista Brasileira de Educação Física e Esporte, v. 25, n. 1, p. 7-18, 2011.

SCIELO. [Pesquisa de artigos]. Disponível em: < http://www.scielo.org/php/index.php>. Acesso em: 15 jul. 2015.

TANI, Go. Editoração de periódicos em Educação Física/Ciências do Esporte: dificuldades e desafios. Revista Brasileira de Ciências do Esporte, v. 36, n. 4, p. 715-722, 2014.

TALBOTT, Margareth; HAAG, Herbert; KESKINEN, Kari. Directory of Sport Science. 6th ed. Berlin: International Council of Sport Science and Physical Education (ICSSPE), 2013.

VAN TULDER, Maurits et al. Updated method guidelines for systematic reviews in the Cochrane Collaboration Back Review Group. Spine, v. 28, n. 12, p. 1290-1299, 2003.

\section{Apoio:}

